Article

\title{
Effect of Bifunctional Montmorillonite on the Thermal and Tribological Properties of Polystyrene/Montmorillonite Nanocomposites
}

\author{
Chengcheng Yu®, Yangchuan Ke *, Xu Hu, Yi Zhao, Qingchun Deng and Shichao Lu \\ Nanotechnology Center of Energy Resources, CNPC Nanochemistry Key Laboratory, College of Science, \\ China University of Petroleum, Beijing 102249, China; yccycc9999@163.com (C.Y.); xuhu0001@126.com (X.H.); \\ yccycc9999@126.com (Y.Z.); qingchundeng@163.com (Q.D.); shichaolu@yeah.net (S.L.) \\ * Correspondence: kyc010@sohu.com
}

Received: 26 April 2019; Accepted: 7 May 2019; Published: 8 May 2019

check for updates

\begin{abstract}
In this work, the effect of doubly functionalized montmorillonite (MMT) on the structure, morphology, thermal, and tribological characteristics of the resulting polystyrene (PS) nanocomposites was investigated. The modification of the MMT was performed using a cationic surfactant and an anionic surfactant or a silane coupling agent to increase the compatibility with PS matrix. The polystyrene/organo-montmorillonite (PS/OMMT) nanocomposite particles were prepared by soap-free emulsion polymerization. The OMMT was studied using Fourier-transform infrared (FTIR), $\mathrm{X}$-ray diffraction (XRD), and thermogravimetric analysis (TGA). The structural and morphological changes of PS/OMMT nanocomposites were further characterized by dynamic light scattering (DLS), scanning electron microscopy (SEM), and transmission electron microscopy (TEM). The thermal stability of all the PS/OMMT nanocomposites was higher than that of the pure PS. The anti-wear properties of the polyalphaolefin $(\mathrm{PAO})$ were significantly improved due to the introduction of the PS/OMMT nanocomposite particles. The nanocomposites prepared by a cationic surfactant and a silane coupling agent exhibited the best thermal stability and tribological performance. Our results provide the valuable insights needed to guide the design of lubrication and friction reducing materials.
\end{abstract}

Keywords: doubly functionalized montmorillonite; polystyrene; soap-free emulsion polymerization; thermal stability; tribological property

\section{Introduction}

Clay-polymer nanocomposites have received great attention in recent years due to their exceptional properties, such as increased thermal stability, high fire resistance, and enhanced mechanical characteristics, compared with traditional polymer composites [1,2]. The improvement of many properties of clay-polymer nanocomposites could be achieved using a relatively low clay loading (usually $<10 \mathrm{wt} \%$ ) in a polymer matrix [3]. Among the layered silicates, montmorillonite (MMT) was one of the most widely utilized to fabricate clay-polymer nanocomposite, mainly because the MMT was easily available with a high aspect ratio and high expansion capacity [4]. The unit crystal structure of the MMT consisted of two silicon tetrahedral sheets and a central sheet of alumina octahedrons. The negative charge was generated on the surfaces of the MMT layers due to the isomorphic substitutions of lower valance ions $\left(\mathrm{Mg}^{2+}, \mathrm{Fe}^{2+}\right)$ for the central atoms $\left(\mathrm{Al}^{3+}, \mathrm{Si}^{4+}\right)$ in the interior crystal layers of the MMT [5]. To neutralize the negative charges, hydrated cations $\left(\mathrm{Na}^{+}, \mathrm{Ca}^{2+}\right)$ were electrostatically adsorbed inside the interlayer space and on the surface of the MMT. Therefore, the natural state of the MMT was a hydrophilic character, which was inherently incompatible with the vast majority of organic polymers [6]. The poor affinity between the hydrophilic MMT and the 
hydrophobic polymer will not result in a clay-polymer nanocomposite with improved properties compared with the pure polymer matrix. To obtain the highest enhancement of properties, the surface modification of the MMT was desirable to increase the interfacial interactions between the MMT and the polymer matrix [7]. The surface treatment not only enhanced the compatibility of the MMT with the organic polymer, but also enlarged the interlayer space between the layers of MMT.

The most traditional and convenient method for the MMT modification was ion exchange reaction with quaternary alkylammonium salts [8]. However, the ammonium surfactants could not provide an effective thermal stability for high temperature applications because the decomposition of the ammonium surfactants could be initiated above $200^{\circ} \mathrm{C}$ [9]. Thus, the modification of the MMT with phosphonium surfactants has attracted much interest from researchers. Several research papers found that the thermal stability of organoclays modified with phosphonium surfactants was superior to that of organoclays modified with ammonium surfactants $[10,11]$. On the other hand, the anionic surfactant was also used to improve the thermal stability of the organoclays [12]. However, it could be rather difficult to significantly expand the interlayer space of the MMT via the anionic surfactant alone. Therefore, a novel kind of organo-montmorillonite (OMMT) by the synergistic effect between the anionic and cationic surfactants has been prepared in recent years [13]. Another method for the modification of the MMT involved the use of silane coupling agents. These silanes could react with the MMT OH groups to form the chemical bonds with a covalent character between the molecules of the silane and the surface of the MMT [14]. The grafting reaction mainly occurred at the broken edges and at the structural defects situated at the external surfaces of the MMT layers [15]. However, the employment of both a phosphonium surfactant and an anionic surfactant, or both a phosphonium surfactant and a silane coupling agent, to fabricate the OMMT to increase the dispersion degree in the polymer matrix was rarely reported.

Polystyrene (PS) is a synthetic thermoplastic that is widely used in industry due to its excellent performance of high abrasion resistance, strong plasticity and load bearing capacity [16]. However, the relatively weak thermal stability and heat resistance of PS has become a significant challenge, hindering its further applications in a variety of areas. To compensate this demerit, the addition of inorganic clay to the PS matrix can be further helpful to enhance the properties of the PS matrix [17]. Recently, an attractive technique to synthesize the clay-polymer nanocomposite is the emulsion polymerization due to the great advantage of controlled morphology and employment of water as a dispersion medium [18]. However, the surfactants were usually used in emulsion polymerization to provide colloidal stability, which may affect the final properties of the nanocomposite. The soap-free emulsion polymerization is a clean and effective way to prepare clay-polymer particles due to the use of little to no surfactant (below critical micelle concentration) in such a polymerization system $[19,20]$. Though the soap-free emulsion polymerization was extensively studied for the preparation of clay-polymer nanocomposites, a few papers related to the investigation of the effect of doubly organo-modified montmorillonite on the final properties of the resulting PS/OMMT nanocomposites have been published so far.

In this work, two kinds of doubly organo-modified MMT were successfully prepared by using both a cationic surfactant and an anionic surfactant or both a cationic surfactant and a silane coupling agent. Then, the PS/OMMT nanocomposites were produced using styrene monomer and the obtained OMMT samples via the soap-free emulsion polymerization. The obtained PS/OMMT nanocomposites were dispersed into polyalphaolefin (PAO) to create lubricants. The effect arising from the doubly organo-modified MMT on the structure, morphology, thermal, and tribological properties of the PS/OMMT nanocomposites were studied and evaluated.

\section{Materials and Methods}

\subsection{Materials}

The natural sodium montmorillonite (MMT, cationic exchange capacity (CEC) of $100 \mathrm{mmol} / 100 \mathrm{~g}$ ) was provided by Huai An Saibei Technology Co. Ltd., Zhangiiakou, China. The tributyltetradecylphosphonium 
chloride (TTPC, 97\%), sodium lauryl sulfonate (SLS, 99\%), and $\gamma$-methacryloxypropyltrimethoxysilane (KH570, 97\%) were purchased from Aladdin Industrial Corporation, Shanghai, China. Styrene (St, 98\%), divinylbenzene (DVB, 80\%), methacrylic acid (MAA, 98\%), and potassium persulfate (KPS, 99\%) were supplied by the Tianjin Guang fu Fine Chemicals Research Institute, Tianjin, China. The St was washed with $\mathrm{NaOH}$ solution to remove the polymerization inhibitors, and then distilled under reduced pressure before use. Polyalphaolefin (PAO, 99\% purity) was provided by Shanghai Fox Chemical Technology, Shanghai, China. Other reagents were of analytical grade and used as received. Deionized water was applied for all experiments.

\subsection{Preparation of OMMT}

\subsubsection{Preparation of P-MMT}

The modification of MMT with TTPC was carried out by the method reported in a previous paper [21]. Briefly, $2.5 \mathrm{~g}$ of MMT was dispersed into $75 \mathrm{~mL}$ of deionized water with stirring for $30 \mathrm{~min}$ at $75{ }^{\circ} \mathrm{C}$. Then, $25 \mathrm{~mL}$ of aqueous solution containing the TTPC surfactant equivalent to $1.2 \mathrm{CEC}$ of MMT was slowly added into the clay dispersion. The mixture was further stirred at $75^{\circ} \mathrm{C}$ for $11 \mathrm{~h}$ and then filtered by vacuum filtration followed by washing with deionized water several times to remove excess TTPC molecules. The final product was dried at $60^{\circ} \mathrm{C}$ for one day in a vacuum oven then ground into powder. The sample formed was referred to as P-MMT. The preparation process was shown in Figure 1 (Stage A).

\subsubsection{Preparation of P-SLS-MMT}

The P-MMT was further modified using the SLS surfactant to produce the doubly organo-modified MMT (P-SLS-MMT) as shown in Figure 1 (Stage B) [22]. In detail, $2.5 \mathrm{~g}$ of P-MMT and $75 \mathrm{~mL}$ of deionized water were introduced in the reaction flask and stirred for $0.5 \mathrm{~h}$ at $75^{\circ} \mathrm{C}$. Then, the desired amount of SLS surfactant was dissolved in $25 \mathrm{~mL}$ of deionized water and added slowly into the suspension. The amount of SLS used was equivalent to 0.6 CEC of MMT. The mixture was stirred vigorously for $9 \mathrm{~h}$ at $75^{\circ} \mathrm{C}$. Finally, the resultant product was separated by centrifugation and washed four times using a mixture of ethanol/deionized water to remove the residual surfactants. The final product was dried at $60^{\circ} \mathrm{C}$ overnight to obtain the P-SLS-MMT sample.

\subsubsection{Preparation of P-KH570-MMT}

The silane functionalization of P-MMT was carried out following the method described in a previous report [23]. In a typical experiment (Figure 1 (Stage C)), the KH570 (2.483 g) was dissolved into methanol $(90 \mathrm{~mL}) /$ deionized water $(10 \mathrm{~mL})$ solution with stirring, and the $\mathrm{pH}$ of the mixture was adjusted to 4.0 with acetic acid. The mixture was stirred for $1 \mathrm{~h}$ at room temperature to obtain the hydrolyzed KH570. Then, $2.5 \mathrm{~g}$ of P-MMT was introduced into the mixture and the suspension was further mechanically stirred with reflux at $75^{\circ} \mathrm{C}$ for $24 \mathrm{~h}$. Finally, the product was filtered and washed with methanol to remove the undesired siane molecules, and then dried under a vacuum oven at $60^{\circ} \mathrm{C}$ for $24 \mathrm{~h}$. The collected product was named as P-KH570-MMT.

\subsection{Preparation of PS/OMMT Nanocomposite}

The soap-free emulsion polymerization was applied to prepare the PS/OMMT nanocomposites according to previous reports [24,25]. Briefly, a mixture of OMMT $(0.6 \mathrm{~g}, 3.0 \mathrm{wt} \%$ based on St), St $(20.0 \mathrm{~g})$, DVB $(1.8 \mathrm{~g})$ and an auxiliary monomer MAA $(1.0 \mathrm{~g})$ was ultrasonicated for $10 \mathrm{~min}$ in an ice bath and then magnetically stirred at room temperature for $1 \mathrm{~h}$ (Figure 1 (Stage D)). Meanwhile, $0.1 \mathrm{~g}$ of SLS was dissolved in $180 \mathrm{~mL}$ of deionized water with stirring for $30 \mathrm{~min}$ under nitrogen atmosphere. Both were later mixed in a 500-mL round-bottomed flask and mechanically stirred at $75^{\circ} \mathrm{C}$ for $30 \mathrm{~min}$ under nitrogen atmosphere. Then, $0.109 \mathrm{~g}$ of KPS initiator was dissolved in $40 \mathrm{~mL}$ of deionized water and slowly introduced into the reactor. The resulting mixture was polymerized at $75{ }^{\circ} \mathrm{C}$ for $24 \mathrm{~h}$ 
under nitrogen atmosphere and mechanical stirring (Figure 1 (Stage E)). The final products were obtained by centrifugation and washing three times using excess hot ethanol to remove the unbound polymers, then dried overnight at $60^{\circ} \mathrm{C}$. The nanocomposite prepared with P-MMT, P-SLS-MMT, and P-KH570-MMT was abbreviated as PS/P-MMT, PS/P-SLS-MMT, and PS/P-KH570-MMT, respectively.

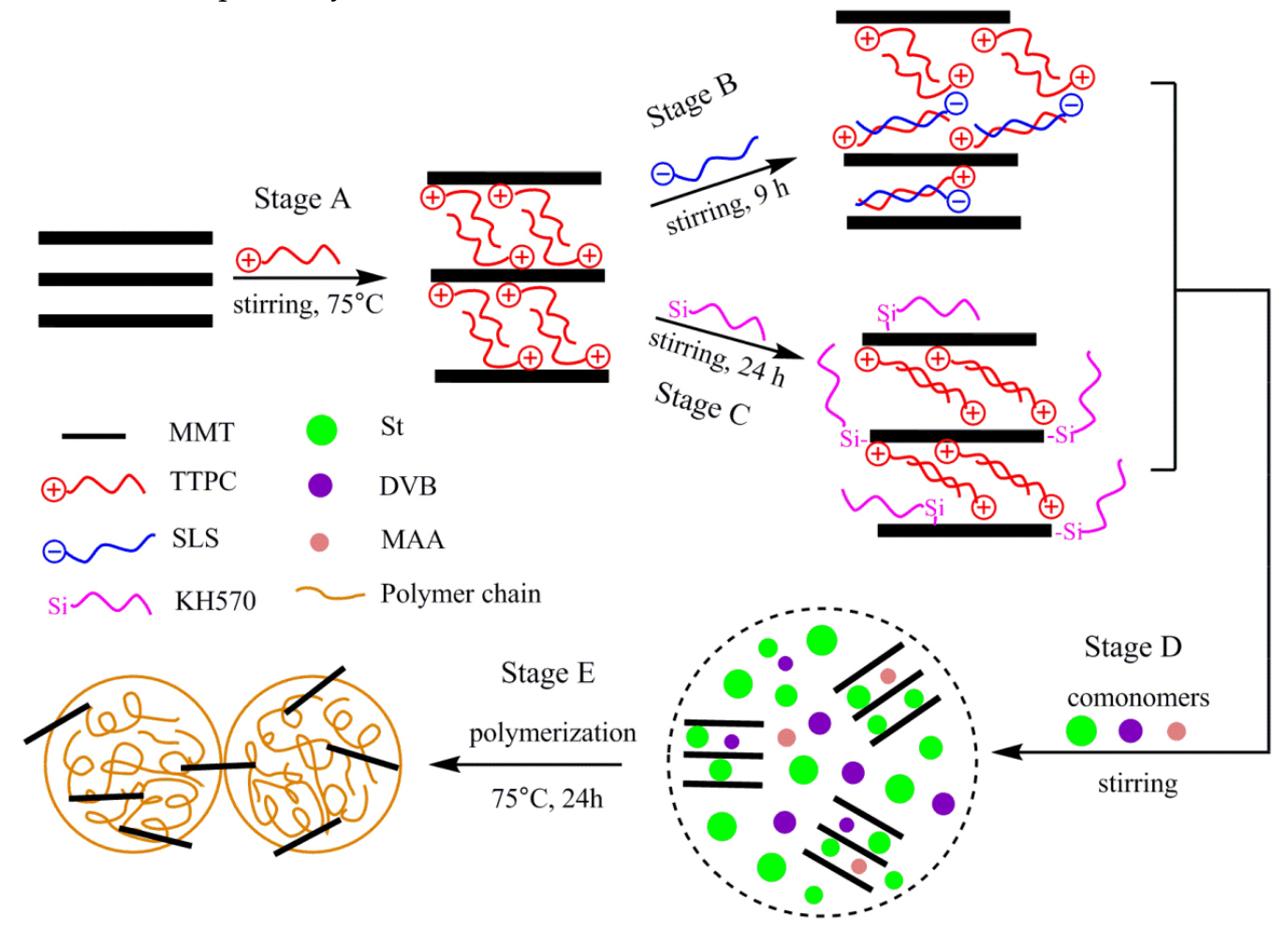

Figure 1. Schematic representation of the processes of preparing the organo-montmorillonite (OMMT) and the polystyrene (PS)/OMMT nanocomposites.

\subsection{Preparation of the PAO-PS/OMMT Lubricant}

The PAO-PS/OMMT lubricant was prepared to investigate the tribological performance of the PS/OMMT nanocomposites as additives. The PS/OMMT nanocomposites (1.0 wt $\%$ based on PAO) were added to the PAO, and the mixture was mechanically stirred at $1000 \mathrm{rpm}$ for $30 \mathrm{~min}$ followed by ultrasonication for $1 \mathrm{~h}$ at room temperature to allow the dispersion and homogenization of the nanocomposites in the PAO.

\subsection{Characterization}

Fourier-transform infrared (FTIR) spectra were conducted over the range of $4000-400 \mathrm{~cm}^{-1}$ using an FTS-3000 spectrophotometer (American Digilab) via a KBr pressed disk technique at room temperature.

X-ray diffraction (XRD) measurements were carried out with a Bruker D8 Advance X-ray Diffractometer (Stadi P, Karlsruhe, Germany) using Cu-Ka radiation $(\lambda=0.1540 \mathrm{~nm})$ with a scanning rate of $2^{\circ} / \mathrm{min}, 40 \mathrm{kV}$, and $30 \mathrm{~mA}$ over the $2 \theta$ range of $1.5^{\circ}-20^{\circ}$ by a scanning interval of $0.02^{\circ}$. The corresponding basal space was computed by applying the Bragg's Law.

Dynamic light scattering (DLS) was performed using a Malvern Mastersizer 2000 (Malvern Instruments, Malvern, UK) to determine the particle size and size distribution of the samples at room temperature.

Scanning electron microscopy (SEM, SU8010, Hitachi, Tokyo, Japan) coupled with an energy dispersing spectrometer (EDS) was used to study the surface morphology and elements of the nanocomposites. The samples were coated with a thin layer of gold prior to SEM observation. 
The EDS analysis was registered three times in different points, and the result was the average of three obtained values.

Transmission electron microscopy (TEM) analyses were performed on a JEM-2100 TEM operating at an accelerating voltage of $200 \mathrm{kV}$.

Thermogravimetric analysis (TGA) was carried out on a NETZSCH thermogravimetric analyzer (TGA, STA409PC, Bavaria, Germany) at a heating rate of $10{ }^{\circ} \mathrm{C} / \mathrm{min}$ from $25^{\circ} \mathrm{C}$ to $800{ }^{\circ} \mathrm{C}$ under a nitrogen flow. Differential thermogravimetry (DTG) curves were calculated from the TGA results.

The tribological measurements were performed using a four-ball tester (MRS-1J, Jinan, China) under a load of $392 \mathrm{~N}$ at a rotating speed of $1450 \mathrm{r} / \mathrm{min}$ for $1 \mathrm{~h}$ at room temperature. Prior to testing, the steel bearing balls GCr15 (diameter of $12.7 \mathrm{~mm}$, grade 10) were cleaned ultrasonically for $30 \mathrm{~min}$ with ethanol. The average values of coefficient of friction $(\mathrm{COF})$ were reported from three measurements of each sample.

\section{Results}

\subsection{Surface Treatments of Montmorillonite}

\subsubsection{FTIR Analysis}

The FTIR spectra of MMT, PMMT, P-SLS-MMT, and P-KH570-MMT are given in Figure 2. In the spectra of MMT, the broad absorption bands at 3446.4 and $1643.4 \mathrm{~cm}^{-1}$ corresponded to the $-\mathrm{OH}$ stretching vibration and $\mathrm{H}-\mathrm{O}-\mathrm{H}$ bending vibration of adsorbed water within MMT interlayer, respectively. The characteristic absorption peak at $3632.5 \mathrm{~cm}^{-1}$ was attributed to the stretching vibration of the $\mathrm{Al}-\mathrm{OH}$ and $\mathrm{Si}-\mathrm{OH}$ in the silicate layers, and this - $\mathrm{OH}$ group was responsible for the reaction with the silane coupling agent [26]. The bands at 1036.1 and $793.4 \mathrm{~cm}^{-1}$ were representative of the stretching vibration of $\mathrm{Si}-\mathrm{O}$ and $\mathrm{Si}-\mathrm{O}-\mathrm{Al}$, respectively. In addition of these characteristic peaks of MMT, novel vibration bands related to surfactants and/or silane coupling agents appeared in the spectra of OMMT (Figure 2B-D). For the P-MMT, the asymmetric and symmetric stretching vibration of $-\mathrm{CH}_{2}$ of phosphonium surfactants was observed at 2928.2 and $2854.0 \mathrm{~cm}^{-1}$, respectively. This is direct evidence for the successful intercalation of TTPC surfactants into the interlayer space of MMT. In comparison with the P-MMT, the intensity of the absorption bands at 2928.2 and $2854.0 \mathrm{~cm}^{-1}$ increased for the P-SLS-MMT, which can be reasonably attributed to the introduction of the SLS surfactants. Besides, the absorption band at $1090.2 \mathrm{~cm}^{-1}$ corresponded to the asymmetric stretching vibration of $-\mathrm{SO}_{3} \mathrm{H}$ group of SLS surfactants. These results indicated that the TTPC and SLS surfactants were synergistically incorporated into the interlayer space of MMT. The spectrum of P-KH570-MMT not only had the characteristic bands of P-MMT, but also exhibited a novel band at $1723.9 \mathrm{~cm}^{-1}$, which was assigned to the stretching vibration of the $\mathrm{C}=\mathrm{O}$ in the $\mathrm{KH} 570$ molecules. In addition, higher intensity of the absorption bands at 2928.2 and $2854.0 \mathrm{~cm}^{-1}$ were also found for the P-KH570-MMT sample, implying that KH570 was successfully grafted on the surfaces and edges of the silicate layers [27]. These observations suggested that the MMT was doubly organo-modified by a phosphonium surfactant and a silane coupling agent. It is worth mentioning that a significant decrease of the relative intensity of the bands at 3632.5-3446.4 $\mathrm{cm}^{-1}$ and $1639.8 \mathrm{~cm}^{-1}$ was observed for the OMMT compared with the MMT, which indicated that the surface of OMMT changed from a hydrophilic to a hydrophobic character and the content of water over OMMT decreased. The above results indicated that the target doubly organo-modified MMT was successfully synthesized. 


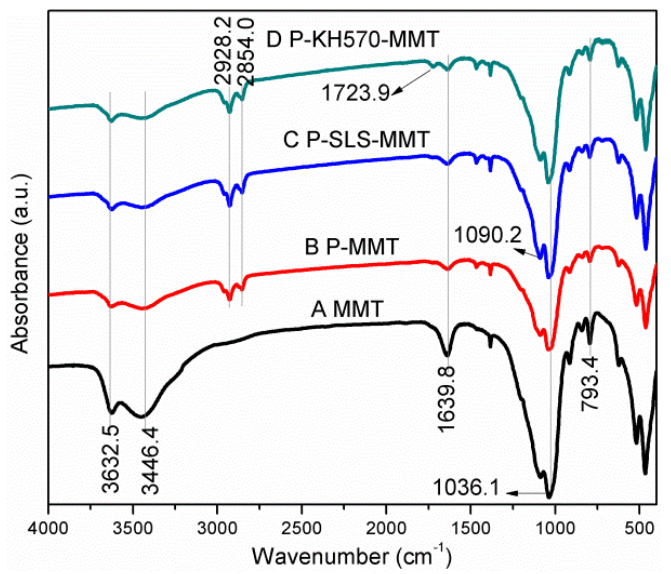

Figure 2. Fourier-transform infrared (FTIR) spectra of (A) sodium montmorillonite (MMT), (B) P-MMT, (C) P-SLS-MMT, and (D) P-KH570-MMT.

\subsubsection{XRD Analysis}

The XRD patterns obtained for the MMT and OMMT are presented in Figure 3. The MMT showed a typical XRD reflection at $2 \theta=7.28^{\circ}$, corresponding to a basal spacing of $1.21 \mathrm{~nm}$ according to Bragg's law. This value is in agreement with similar hydrated clays reported in the literature [28]. The significant increase in the interlayer space of the MMT was observed after the modification with surfactants. In the case of P-MMT, the characteristic peak shifted from $7.28^{\circ}$ to $3.84^{\circ}$, corresponding to an increase in basal space from $1.21 \mathrm{~nm}$ to $2.36 \mathrm{~nm}$. This result confirms that the intercalation of phosphonium surfactant was really achieved, which is consistent with the FTIR results. In the XRD spectrum of P-SLS-MMT, the distribution of interlayer space of platelets was characterized by two prominent reflections that appeared at $2 \theta=2.87^{\circ}$ and $5.79^{\circ}$, corresponding to interlayer spaces of $3.07 \mathrm{~nm}$ and $1.52 \mathrm{~nm}$, respectively. The basal space of P-SLS-MMT was $0.71 \mathrm{~nm}$ higher than that of P-MMT, which indicated that SLS successfully entered the interlayer space of P-MMT and cation-anion type OMMT was prepared. The anionic surfactants can form ion-pairs with the cationic surfactants to intercalate into the interlayer space of MMT. This result was also observed by other researchers $[29,30]$. The appearance of a second peak in the XRD pattern of P-SLS-MMT was attributed to the (002) reflection. The diffraction peak of P-KH570-MMT at $4.21^{\circ}$ corresponded to an interlayer space of $2.09 \mathrm{~nm}$. Compared with P-MMT, the decrease in the interlayer space of P-KH570-MMT was mainly due to partly intercalated cationic surfactants becoming washed out with the use of hydroalcoholic solution as a solvent in the silylation reaction. This result indicated that the KH570 was mainly grafted onto the broken edges and external surfaces or undergoing ion exchange with the pre-existing surfactants in a very low amount, thus merely had a significant impact on the interlayer structure of P-MMT [31].

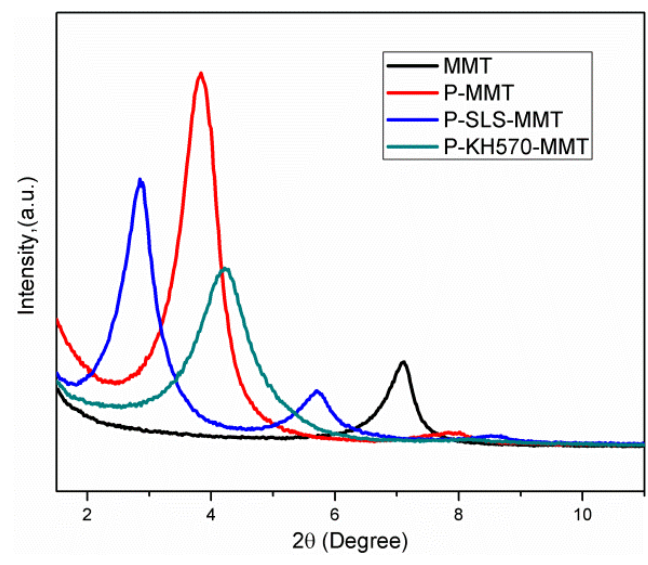

Figure 3. XRD patterns of MMT, P-MMT, P-SLS-MMT, and P-KH570-MMT. 


\subsubsection{TGA and DTG Analysis}

Figure 4 shows the thermogravimetric analysis (TGA) and derivative thermogravimetry (DTG) curves of MMT, PMMT, P-SLS-MMT, and P-KH570-MMT samples. In Table 1, the mass loss associated with the different temperature ranges is listed. Two distinct thermal degradation events were obtained in the DTG curves of the MMT. The first mass loss, occurring at a temperature of $75^{\circ} \mathrm{C}$, was assigned to the elimination of physically adsorbed water, and the second at $660^{\circ} \mathrm{C}$ corresponded to the dihydroxylation of clay layers [32]. The mass loss of OMMT was higher than that of MMT at 200-600 ${ }^{\circ} \mathrm{C}$, which was evidence of intercalated surfactants and/or grafted silane coupling agents. For the P-MMT, the mass loss below $200^{\circ} \mathrm{C}$ was lower when compared with the MMT, implying less adsorbed water in the P-MMT. Furthermore, the mass loss of the P-MMT between $200^{\circ} \mathrm{C}$ and $600^{\circ} \mathrm{C}$ was obviously higher than that of the MMT, which was attributed to the degradation of adsorbed surfactant molecules on the external surface and of intercalated surfactant molecules in the interlayer space of the MMT. The overall mass loss of P-MMT (20.7 wt \%) was higher than that of MMT (5.6 wt \%). Compared with P-MMT, a greater mass loss in the range of $200{ }^{\circ} \mathrm{C}$ to $600{ }^{\circ} \mathrm{C}$ was found in P-SLS-MMT, which could be attributed to the intercalation of SLS molecules into the interlayer space of P-MMT. In addition, the maximum mass loss rate temperature of P-SLS-MMT occurred at $499{ }^{\circ} \mathrm{C}$, higher than $15{ }^{\circ} \mathrm{C}$ in P-MMT, indicating the thermal properties of P-MMT were enhanced owing to the introduction of the SLS molecules. These results suggested that the SLS molecules were successfully intercalated into the interlayer space of the P-MMT. This result was consistent with the results of XRD analysis. In the case of P-KH570-MMT, the first mass loss occurred at a temperature below $200{ }^{\circ} \mathrm{C}$ which was attributed to the evaporation of adsorbed water and/or of free molecules of solvent in the pores of MMT. The mass loss observed over the range of $200-600^{\circ} \mathrm{C}$ was assigned to the loss of surfactant molecules combined with the decomposition of adsorbed and/or grafted KH570 molecules introduced during the silylation reaction. Compared with the P-MMT, the observed increase in mass loss for the P-KH570-MMT between $200{ }^{\circ} \mathrm{C}$ and $600{ }^{\circ} \mathrm{C}$ was attributed to the intercalated and/or grafted silane molecules. Combining this with the result of XRD, the interlayer space of P-KH570-MMT was smaller than that of P-MMT, the increasing amount of KH570 molecule was mainly grafted on the broken edges and the external surface of MMT, not intercalating in the interlayer space of MMT [33].
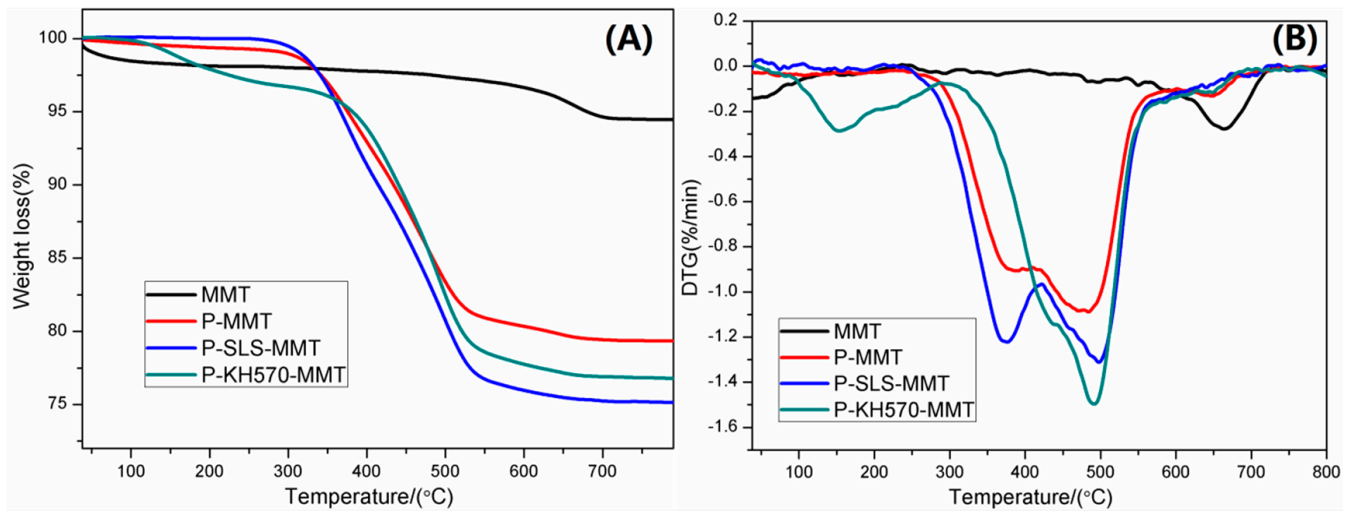

Figure 4. (A) Thermogravimetric analysis (TGA) and (B) Derivative thermogravimetry (DTG) curves of MMT, P-MMT, P-SLS-MMT, and P-KH570-MMT.

Table 1. Relative mass loss during decomposition of investigated samples (wt \%).

\begin{tabular}{|c|c|c|c|}
\hline \multirow{2}{*}{ Sample } & \multicolumn{3}{|c|}{ Temperature Range } \\
\hline & $<200 \pm 1.5^{\circ} \mathrm{C}$ & $200-600 \pm 1.9^{\circ} \mathrm{C}$ & $30-800 \pm 2.2^{\circ} \mathrm{C}$ \\
\hline MMT & 1.9 & 1.5 & 5.6 \\
\hline P-MMT & 0.6 & 19.0 & 20.7 \\
\hline P-SLS-MMT & 0.2 & 23.9 & 24.9 \\
\hline P-KH570-MMT & 2.3 & 19.9 & 23.3 \\
\hline
\end{tabular}




\subsection{Characterization of PS/OMMT Nanocomposite}

\subsubsection{FTIR Analysis}

The FTIR spectra of the PS, PS/P-MMT, PS/P-SLS-MMT, and PS/P-KH570-MMT are shown in Figure 5. In the case of PS, the characteristic bands at 3027.6 and $2914.0 \mathrm{~cm}^{-1}$ were attributed to the $\mathrm{CH}$ aromatic stretching vibrations and $\mathrm{CH}_{2}$ asymmetric stretching vibrations, respectively. Two absorption bands at 1602.6 and $1449.1 \mathrm{~cm}^{-1}$ were ascribed to the stretching vibration of the aromatic $\mathrm{C}=\mathrm{C}$. There were two strong absorption bands at 763.0 and $691.1 \mathrm{~cm}^{-1}$ that corresponded to the $\mathrm{CH}$ out-of-plane deformation of benzene rings. In addition, the peak at $1725.7 \mathrm{~cm}^{-1}$ was due to the $\mathrm{C}=\mathrm{O}$ stretching vibration of methacrylic acid. These observations indicate that the polymerization reaction of styrene monomer has been occurred [34]. The FTIR spectra of PS/P-MMT not only had the characteristic bands of PS, but also exhibited new absorption bands at $1039.7 \mathrm{~cm}^{-1}$, which were assigned to Si-O stretching vibrations of the MMT. This result proved the formation of PS/P-MMT nanocomposites. The presence of the characteristic peak of MMT in the polymer matrix was also observed in the samples of PS/P-SLS-MMT and PS/P-KH570-MMT.

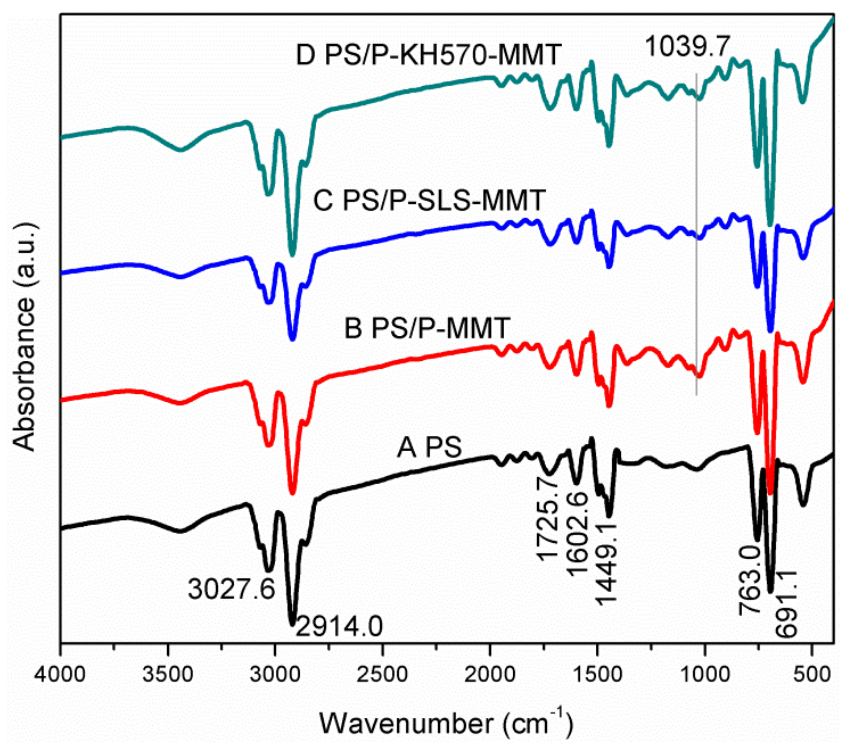

Figure 5. FTIR spectra of (A) PS, (B) PS/P-MMT, (C) PS/P-SLS-MMT, and (D) PS/P-KH570-MMT.

\subsubsection{XRD Analysis}

Figure 6 shows the XRD patterns of the PS, PS/P-MMT, PS/P-SLS-MMT, and PS/P-KH570-MMT nanocomposites. As shown in Figure 6, no characteristic diffraction peak of OMMT was observed for the PS/P-MMT, PS/P-SLS-MMT, or PS/P-KH570-MMT in the range of $1.5^{\circ}-10.0^{\circ}$ of $2 \theta$. This result suggested that the PS chains entered into the interlayer space of OMMT and destroyed the intercalated clay structure, leading to exfoliated structure in the resulting PS/OMMT nanocomposite during the soap-free emulsion polymerization. The clay platelets could be exfoliated in the PS matrix owing to the role of the intercalated phosphonium surfactants, SLS molecules, and/or adsorbed KH570 silanes that obviously enlarged the interlayer space of the MMT, which could provide a bigger space for the ease of PS macromolecular chains penetration. In addition, the complete exfoliation of individual clay platelets in the polymer matrix was also because of the favorable miscibility between the organic clay platelets and polymer matrix [35]. Furthermore, the KH570 molecules that grafted on the broken edges of the MMT could improve the hydrophobicity of the layered silicates, thus increasing their compatibility with the PS matrix [36]. However, the disappearance of XRD peaks does not necessarily suggest complete delamination of the clay platelets. Thus, other analytical tools, such as TEM, were needed to prove the dispersion and degree of exfoliation of the clay platelets. In order to determine the 
deductions from XRD results, the morphology of the nanocomposites was further analyzed by the use of TEM. Figure 7 shows the typical TEM images of the PS and PS/OMMT nanocomposites.

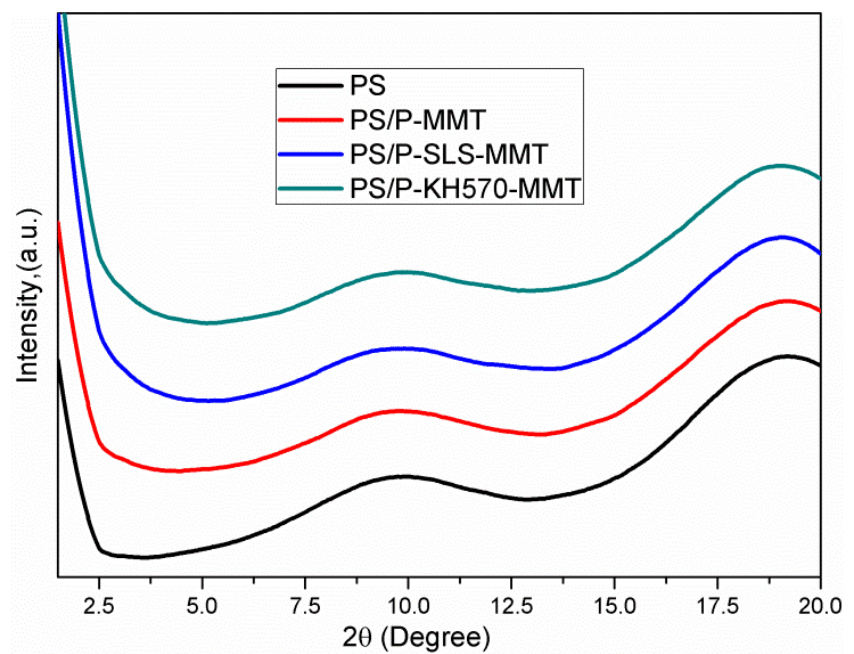

Figure 6. XRD patterns of PS, PS/P-MMT, PS/P-SLS-MMT, and PS/P-KH570-MMT.

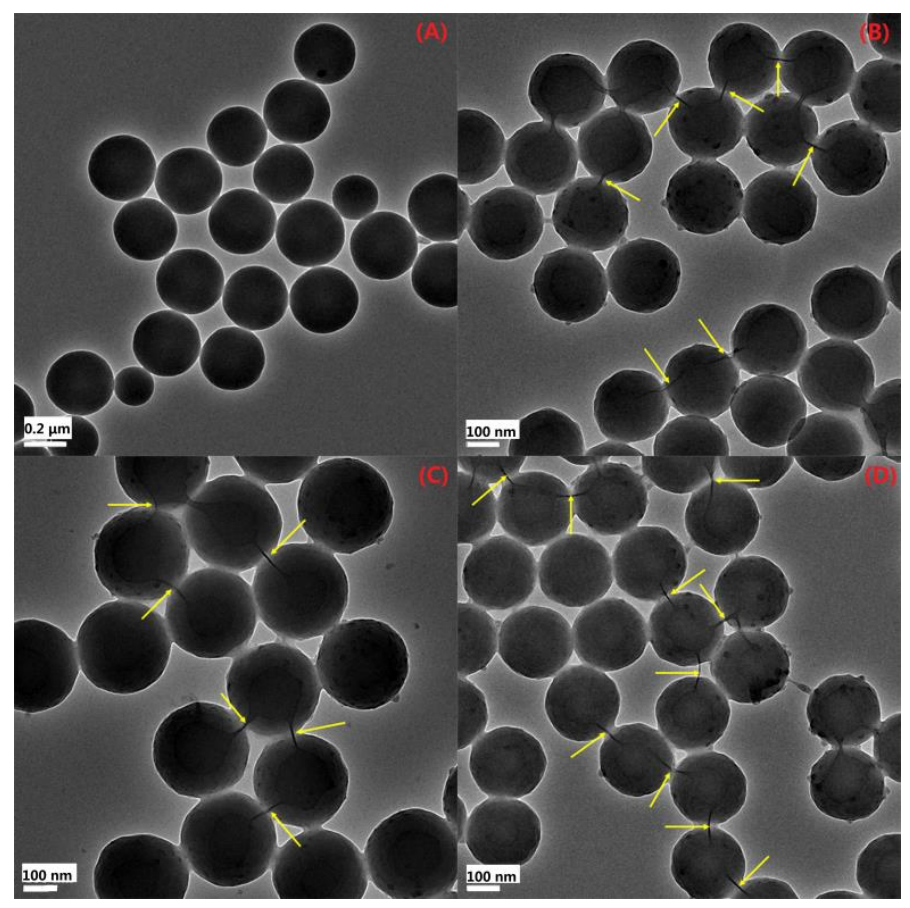

Figure 7. Transmission electron microscopy (TEM) images of (A) PS, (B) PS/P-MMT, (C) PS/P-SLS-MMT, and (D) PS/P-KH570-MMT.

\subsubsection{TEM Analysis}

As shown in Figure 7A, spherical particles could be observed for the pure PS. However, the size distribution of particles was broad, and the particle size was in the range of approximately 200-600 nm. In contrast, when the OMMT was introduced into the polymer matrix, the particle sizes of the PS/OMMT nanocomposites became much smaller, as shown in Figure 7B-D. Moreover, the size distribution of PS/OMMT particles was narrow and monomodal, and the particle size was approximately between $250 \mathrm{~nm}$ and $400 \mathrm{~nm}$. These results indicated that the morphology of the polymer particles was changed by the presence of OMMT. The reason was probably that the movement of the styrene monomers and growth of the PS chains were effectively reduced via the shielding effects of the clay platelets. 
As denoted by the yellow arrows in Figure 7B-D, the existence of exfoliated clay layers encapsulated inside the polymer particles was clearly visible. The TEM images of PS/OMMT nanocomposites showed that the nanoclay layers were completely exfoliated and dispersed homogeneously within the PS matrix. It showed that a highly exfoliated structure of PS/OMMT nanocomposite was obtained, which was in accordance with the corresponding XRD results. This result implied that the clay layers of $3 \mathrm{wt} \%$ OMMT could maintain the polymer colloidal stability, thus resulting resulted in the complete exfoliation of the clay layers and formation of exfoliated structure of PS/OMMT nanocomposites [37].

\subsubsection{DLS Analysis}

Figure 8 shows the size distributions of the pure PS and PS/OMMT nanocomposite samples, and the average particle size data and PDI values are summarized in Table 2. The particle size distributions of all samples showed only one narrow peak, and the average diameters of the polymer particles were in the range of 241.3-378.6 $\mathrm{nm}$. These results were consistent with the results of the TEM analysis. The average particle size of the pure PS was $378.6 \mathrm{~nm}$, while the average particle sizes of the PS/OMMT nanocomposites were $290.4 \mathrm{~nm}, 338.8 \mathrm{~nm}$, and $241.3 \mathrm{~nm}$ for the PS/P-MMT, PS-P-SLS-MMT, and PS/P-KH570-MMT, respectively. The decrease in the average particle size of the nanocomposites was owing to the addition of OMMT would more likely to facilitate the nucleation to form smaller and more uniform particles. On the other hand, the PDI values, which were indicative of the monodispersity of polymer particles, were observed to decrease for the PS/OMMT nanocomposites compared with the pure PS. This observed decrease was owing to the self-arrangement of the modified MMT layers within the PS particles might affect the surface tension and cause fine and stable particles. Moreover, the hydrophobic MMT layers could act as stabilizers to improve the monodispersity of the PS particles [38]. The organic modification of MMT improved its compatibility with the monomer phase and promoted the exfoliation of the MMT, which was beneficial to the encapsulation of clay platelets by the polymer particles. The smallest particle size and PDI value were obtained for the PS/P-KH570-MMT sample, which was due to the ability of the vinyl group of the KH570 molecule to participate in the polymerization reaction.

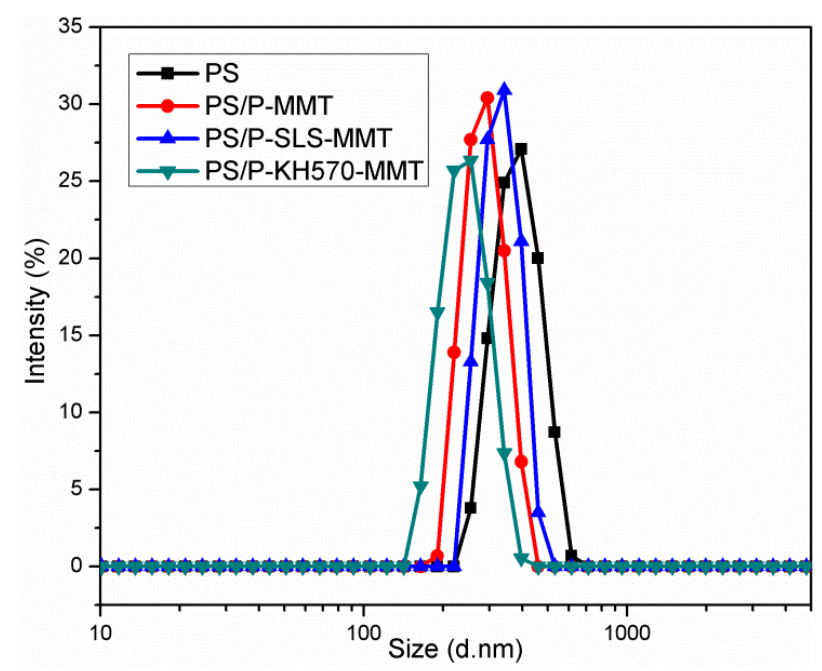

Figure 8. Size distribution curves of PS, PS/P-MMT, PS/P-SLS-MMT, and PS/P-KH570-MMT.

Table 2. Particle size distribution of PS, PS/P-MMT, PS/P-SLS-MMT, and PS/P-KH570-MMT samples.

\begin{tabular}{ccc}
\hline Sample & Z-Average $(\mathbf{n m})$ & PDI \\
\hline PS & $378.6 \pm 8.9$ & 0.232 \\
PS/P-MMT & $290.4 \pm 3.8$ & 0.159 \\
PS/P-SLS-MMT & $338.8 \pm 3.6$ & 0.160 \\
PS/P-KH570-MMT & $241.3 \pm 2.1$ & 0.074 \\
\hline
\end{tabular}




\subsubsection{SEM-EDS Analysis}

Figure 9 shows the SEM images of the PS, PS/P-MMT, PS/P-SLS-MMT, and PS/P-KH570-MMT nanocomposites. As seen in Figure 9A, the particles of pure PS were mostly spherical and the particle size was approximately $380 \mathrm{~nm}$ with a broad size distribution. In particular, a certain degree of coagulation of the particles was observed due to the poor stability. Compared with the pure PS, the particle morphology of the PS/OMMT nanocomposites was changed by the presence of the OMMT. When the OMMT was introduced in Figure 9B-D, the particle size distribution became narrow, and the particle size decreased to 250-350 nm. These results were in good agreement with the results of TEM and DLS. Moreover, each PS/OMMT particle kept good dispersion stability because of the stabilizing effect of OMMT for the polymer particle.

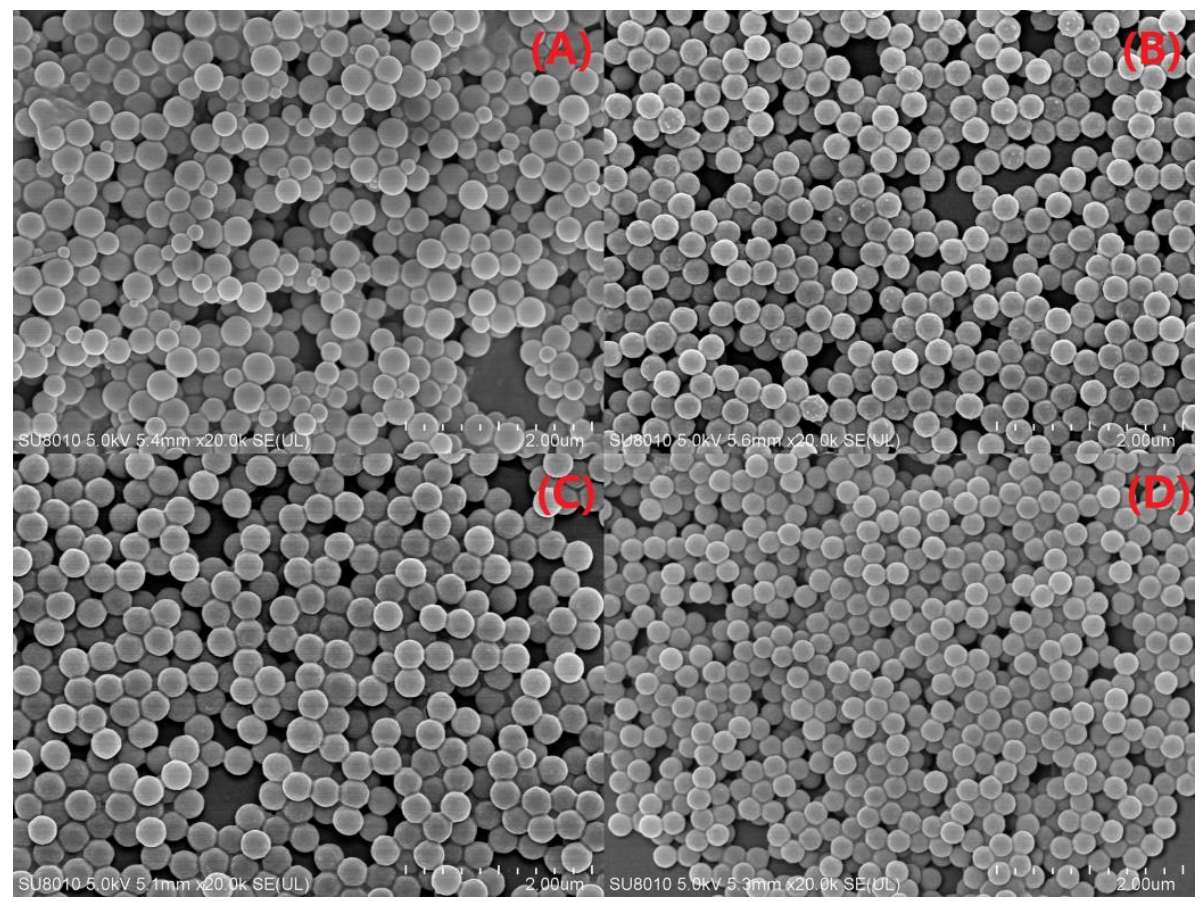

Figure 9. SEM images of (A) PS, (B) PS/P-MMT, (C) PS/P-SLS-MMT, and (D) PS/P-KH570-MMT.

The results of the SEM-EDS analysis are given in Table 3. The most pronounced distinction between the pure PS and the PS/OMMT nanocomposites was the drastic increases in the amount of $\mathrm{Al}$ and $\mathrm{Si}$ content in the PS/OMMT samples. This result indicated that the OMMT was successfully introduced in the polymer matrix.

Table 3. Distribution of the elements in PS, PS/P-MMT, PS/P-SLS-MMT, and PS/P-KH570-MMT samples found by EDS measurement related with SEM images given in Figure 9.

\begin{tabular}{ccccc}
\hline Sample & C (wt \%) & O (wt \%) & Al (wt \%) & Si (wt \%) \\
\hline PS & $68.44 \pm 0.46$ & $30.33 \pm 0.36$ & $0.70 \pm 0.09$ & $0.53 \pm 0.07$ \\
PS/P-MMT & $63.62 \pm 0.24$ & $31.45 \pm 0.40$ & $3.52 \pm 0.17$ & $1.41 \pm 0.12$ \\
PS/P-SLS-MMT & $64.15 \pm 0.30$ & $31.36 \pm 0.38$ & $3.05 \pm 0.19$ & $1.44 \pm 0.13$ \\
PS/P-KH570-MMT & $67.92 \pm 0.33$ & $28.61 \pm 0.29$ & $2.33 \pm 0.11$ & $1.14 \pm 0.12$ \\
\hline
\end{tabular}

\subsubsection{TGA and DTG Analysis}

Figure 10 presents TGA and DTG curves for the pure PS, PS/P-MMT, PS/P-SLS-MMT, and PS/P-KH570-MMT. It can be seen from the TGA curves that the weights of residue left of PS/OMMT nanocomposites at $550{ }^{\circ} \mathrm{C}$ were increased compared with the pure PS, which indicated the presence of 
the MMT in the polymer matrix. Furthermore, in contrast to the pure PS, the PS/OMMT nanocomposites exhibited significantly improved thermal stability, which could be attributed to the addition of OMMT in the polymer matrix [39]. The onset decomposition temperature corresponding to a mass loss of $10 \mathrm{wt} \%\left(\mathrm{~T}_{10 \%}\right)$ of pure PS was $383^{\circ} \mathrm{C}$. As for the PS matrix filled with OMMT, the onset decomposition temperatures of PS/P-MMT, PS/P-SLS-MMT, and PS/P-KH570-MMT were about $399^{\circ} \mathrm{C}, 406{ }^{\circ} \mathrm{C}$, and $416{ }^{\circ} \mathrm{C}$, respectively, that was, $16^{\circ} \mathrm{C}, 23^{\circ} \mathrm{C}$, and $33^{\circ} \mathrm{C}$ higher than that of pure PS. The maximum mass loss temperature ( $T_{\max }$, observed from DTG) was raised from $419^{\circ} \mathrm{C}$ for the pure PS to $440^{\circ} \mathrm{C}, 443^{\circ} \mathrm{C}$, and $449^{\circ} \mathrm{C}$ for PS/P-MMT, PS/P-SLS-MMT, and PS/P-KH570-MMT, respectively. The enhancement in the thermal stability was due to the MMT layers forming a three-dimension network and a labyrinth pathway in the clay-polymer nanocomposite to prevent out-diffusion of the volatile decomposition products during thermal decomposition [40]. Meanwhile, the exfoliated structure of the MMT worked as a mass transport barrier, or a nucleating agent in the matrix, by limiting the heat transfer and absorbing the heat to decelerate the degradation of the polymers [41]. However, it was observed that the $T_{10 \%}$ and $T_{\max }$ of PS/P-SLS-MMT were higher than those of PS/P-MMT. The reason was perhaps that the maximum mass loss temperature of P-SLS-MMT was higher than that of P-MMT, as shown in Figure 4B, due to the electrostatic interaction between the anionic and cationic surfactants. This improvement in thermal stability was also observed in the PS/P-KH570-MMT nanocomposite. These results revealed that the double-modified MMT-containing PS nanocomposites showed higher thermal stability than that of the single-modified one. Interestingly, the $T_{10 \%}$ and $T_{\max }$ of the PS/P-KH570-MMT were higher than those of the PS/P-SLS-MMT. This result indicated that the double bonds of silanes grafting on the edges and surfaces of the MMT could react with styrene monomer increased chemical interaction between the MMT and the polymers, resulting in the improved interface interactions and enhanced the thermal stability [42]. In this case, the PS chains were covalently bonded on the surface of MMT, and the grafted KH570 molecules worked as the "bridge" connecting the PS chains and silicate layers, leading to an increase in the thermal stability.

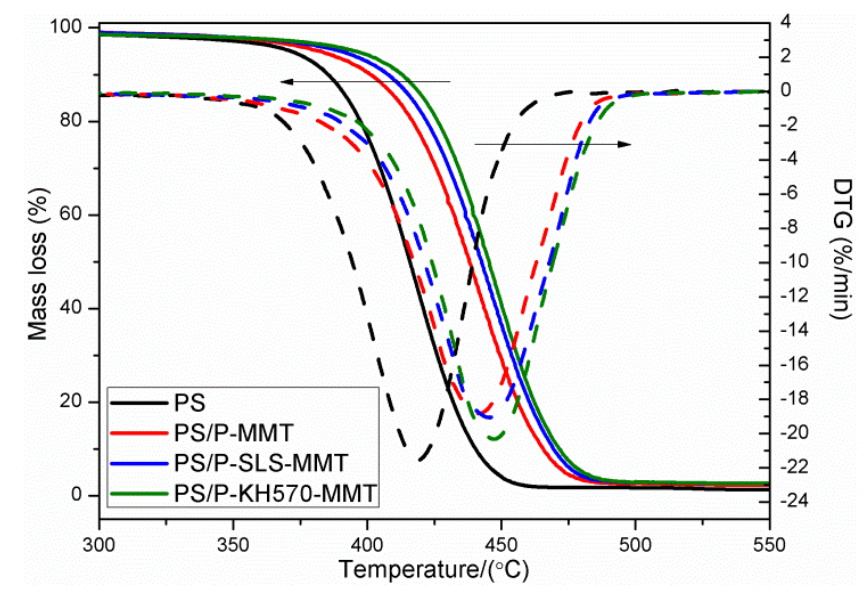

Figure 10. TGA and DTG curves of PS, PS/P-MMT, PS/P-SLS-MMT, and PS/P-KH570-MMT.

\subsubsection{Friction Performance Analysis}

Figure 11 shows the coefficient of friction (COF) versus time of PAO and PAO with PS/OMMT nanocomposite samples. As it can be seen from the figure, the COF of PAO was around 0.095 at the beginning and then increased dramatically to about 0.125 within $1000 \mathrm{~s}$, followed by a stable period of approximately $2700 \mathrm{~s}$. The COF then increased from 0.120 to about 0.145 in the rest of the test. For PAO-PS/P-MMT, the COF rose up sharply from 0.082 to 0.110 , dropped drastically to 0.090 within $250 \mathrm{~s}$, and then experienced a stable period with fluctuation around $1500 \mathrm{~s}$. The COF then increased slowly to 0.115 at the end of the test. The COF of PAO-PS/P-SLS-MMT started at 0.070, increased slowly to about 0.100 around $2200 \mathrm{~s}$, and then remained steady during the rest of the test. The COF of PAO-PS/P-KH570-MMT was 0.070 at the beginning, increased to 0.085 within $250 \mathrm{~s}$, and then rose 
up slowly. At the end of the test, the COF reached 0.090. It can be found from the test results that the adding PS/OMMT nanocomposites to the PAO decreased the COF values and clearly enhanced the friction reduction properties. Furthermore, with the same content of nanocomposite particles, PS/P-KH570-MMT performed the lowest COF value and the best friction reduction properties.

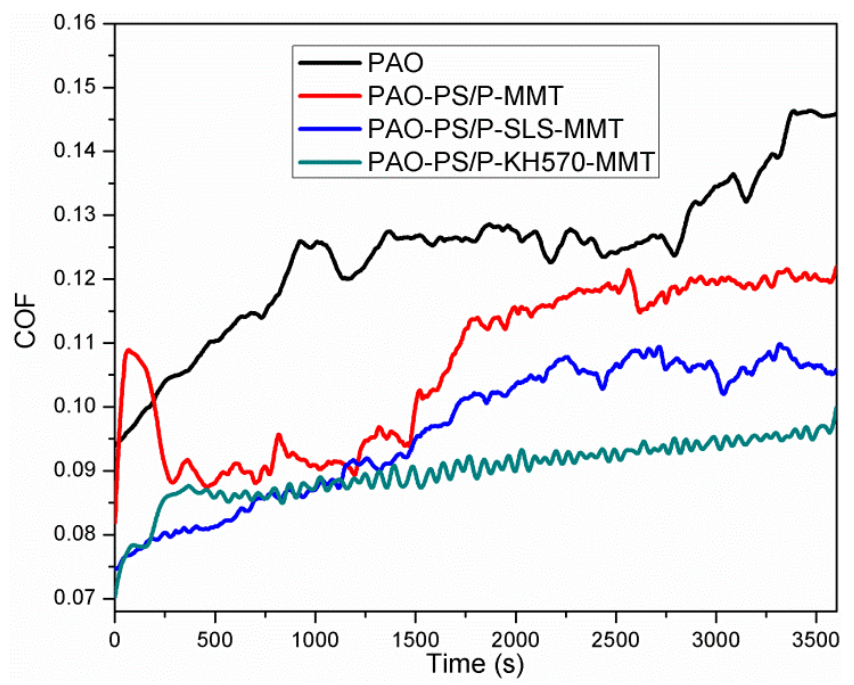

Figure 11. The COF versus time of PAO, PAO-PS/P-MMT, PAO-PS/P-SLS-MMT, and PAO-PS/P-KH570-MMT.

To further characterize the tribological properties for the PS/OMMT nanocomposites, we examined the wear surfaces of the PAO and PAO-PS/OMMT nanocomposites using SEM. Figure 12A-D and Figure 13A-D show the SEM morphology of the wear surfaces of the upper and lower ball of the four-ball machine for PAO, PAO-PS/P-MMT, PAO-PS/P-SLS-MMT, and PAO-PS/P-KH570-MMT, respectively. From Figure 12A, a wide and deep plowing groove was found on the wear surface, indicating serious abrasive wear. This worn morphology was also observed in Figure 13A. However, when the PS/OMMT nanocomposites were added into the PAO, as shown in Figure 12B-D and Figure 13B-D, the grooves on the wear surface became shallower and narrower, which indicated that the surface roughness was improved and the COF was reduced. These results indicated that the PS/OMMT nanocomposites exhibited excellent anti-wear and friction reduction properties in their tribological properties in a lubricant, which were consistent with the results of Figure 11. During the lubrication process, the nanocomposite particles were able to fill in the microgrooves on the wear surfaces and reduce the roughness of the metal surfaces to reduce friction and wear [43]. Furthermore, the nanocomposite particles could support the metal surfaces and prevent them from contacting each other and roll like a bearing ball, thereby reducing the COF and wear [44]. Among the wear surfaces, there was a smoother wear surface with microgrooves and nanogrooves in Figures 12D and 13D. This result suggested that the best anti-wear and friction reduction properties among all the type of nanocomposites were observed with the PS/P-KH570-MMT nanocomposite in this study. This may be due to the smaller PS/P-KH570-MMT nanocomposite particle filling the grooves more effectively than the larger particles. The nanocomposite particles with smaller diameters could interact with the metal surface more effectively and form the transfer film more easily to protect the metal surface and reduce the wear. Meanwhile, with higher thermal stability, the PS/P-KH570-MMT nanocomposite particles might roll better between two wear surfaces and reduce the friction. The above results indicated that the improvements of tribological properties of PS/OMMT nanocomposite particles showed promising applications in the drilling fluid lubrication. 


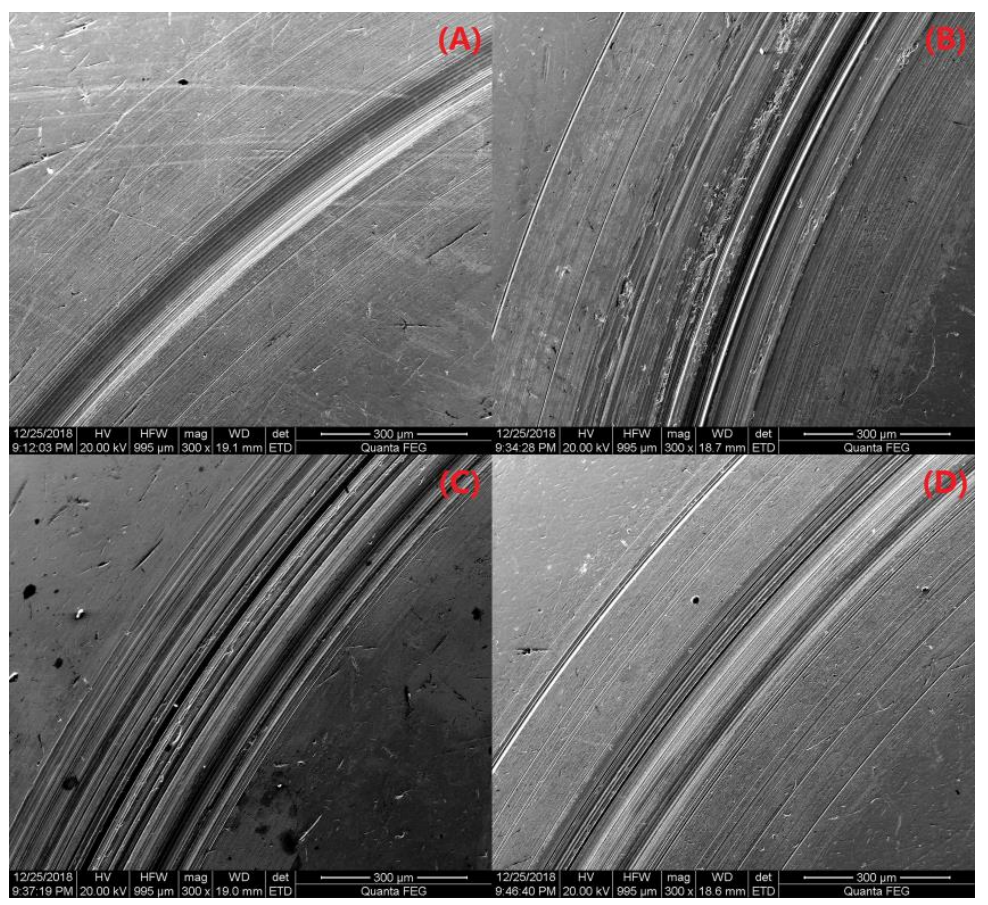

Figure 12. SEM images of the upper ball of (A) PAO, (B) PAO-PS/P-MMT, (C) PAO-PS/P-SLS-MMT, and (D) PAO-PS/P-KH570-MMT.

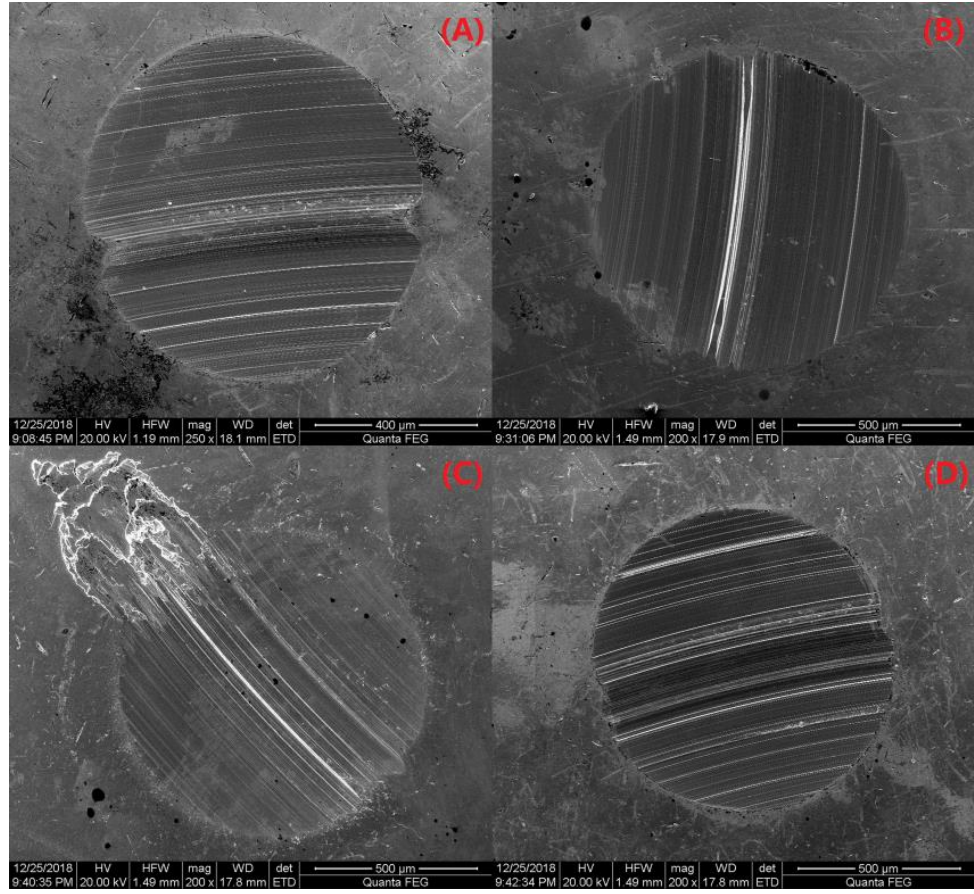

Figure 13. SEM images of the lower ball of (A) PAO, (B) PAO-PS/P-MMT, (C) PAO-PS/P-SLS-MMT, and (D) PAO-PS/P-KH570-MMT.

\section{Conclusions}

Novel PS/OMMT nanocomposite particles were synthesized by soap-free emulsion polymerization in the presence of doubly organo-modified MMTs and investigated. The anionic surfactant, SLS, could be effectively used to further increase the interlayer space of P-MMT by the electrostatic interaction. The silane coupling agent, KH570, could be introduced to the external surfaces and broken edges of the P-MMT due to the silylation reaction. The complete exfoliation of the OMMT within the PS 
matrix was confirmed by XRD and TEM analysis. The introduction of OMMT significantly decreased the average particle size and PDI values of PS, as evidenced by DLS and SEM results, and this became more pronounced in the PS/OMMT nanocomposites filled with P-KH570-MMT. The results of TGA-DTG analysis confirmed that the thermal stability of the PS/OMMT nanocomposites was significantly enhanced compared with pure PS. The $T_{\max }$ increased from $419^{\circ} \mathrm{C}$ of pure PS to $449^{\circ} \mathrm{C}$ of PS/P-KH570-MMT. Moreover, the COF values of PAO-PS/OMMT nanocomposites were well below than that of pristine PAO, indicating increased friction reduction properties. Available results in this work can provide significant guidance for the future synthesis and application of the PS/OMMT nanocomposites in the oil and gas drilling engineering field to improve drilling fluid lubrication.

Author Contributions: Data curation, S.L. and Q.D.; Investigation, C.Y.; Methodology, Y.K.; Software, Y.Z.; Writing-original draft, C.Y.; Writing—review \& editing, X.H.

Funding: This work was funded by the National Natural Science Foundation of China (Grant No. 51674270), National Major Project (Grant No. 2017ZX05009-003), Major project of the National Natural Science Foundation of China (No.51490650), and the Foundation for Innovative Research Groups of the National Natural Science Foundation of China (Grant No. 51821092 and 51521063).

Conflicts of Interest: The authors declare no conflict of interest.

\section{References}

1. Kawasumi, M. The discovery of polymer-clay hybrids. J. Polym. Sci. A: Polym. Chem. 2004, 42, 819-824. [CrossRef]

2. Chafidz, A.; Ali, I.; Mohsin, M.E.A.; Elleithy, R.; Al-Zahrani, S. Nanoindentation and dynamic mechanical properties of PP/clay nanocomposites. J. Polym. Res. 2012, 19, 1-12. [CrossRef]

3. Li, X.; Tang, S.; Zhou, X.; Gu, S.; Huang, K.; Xu, J.; Wang, X.; Li, Y. Synergistic effect of amino silane functional montmorillonite on intumescent flame-retarded SEBS and its mechanism. J. Appl. Polym. Sci. 2017, 134, 44953. [CrossRef]

4. Silva, A.A.; Dahmouche, K.; Soares, B.G. Nanostructure and dynamic mechanical properties of silane-functionalized montmorillonite/epoxy nanocomposites. Appl. Clay Sci. 2011, 54, 151-158. [CrossRef]

5. Sarier, N.; Onder, E.; Ersoy, S. The modification of Na-montmorillonite by salts of fatty acids: An easy intercalation process. Colloids Surf. A Physicochem. Eng. Asp. 2010, 371, 40-49. [CrossRef]

6. Owusu-Adom, K.; Guymon, C.A. Chemical compatibility and reaction-induced exfoliation in photopolymerizable clay nanocomposites. Macromolecules 2009, 42, 180-187. [CrossRef]

7. Xidas, P.I.; Triantafyllidis, K.S. Effect of the type of alkylammonium ion clay modifier on the structure and thermal/mechanical properties of glassy and rubbery epoxy-clay nanocomposites. Eur. Polym. J. 2010, 46, 404-417. [CrossRef]

8. Giannakas, A.; Spanos, C.G.; Kourkoumelis, N.; Vaimakis, T.; Ladavos, A. Preparation, characterization and water barrier properties of PS/organo-montmorillonite nanocomposites. Eur. Polym. J. 2008, 44, 3915-3921. [CrossRef]

9. Ezquerro, C.S.; Ric, G.I.; Miñana, C.C.; Bermejo, J.S. Characterization of montmorillonites modified with organic divalent phosphonium cations. Appl. Clay Sci. 2015, 111, 1-9. [CrossRef]

10. Mittal, V. Modification of montmorillonites with thermally stable phosphonium cations and comparison with alkylammonium montmorillonites. Appl. Clay Sci. 2012, 56, 103-109. [CrossRef]

11. Abdallah, W.; Yilmazer, U. Novel thermally stable organo-montmorillonites from phosphonium and imidazolium surfactants. Thermochim. Acta 2011, 525, 129-140. [CrossRef]

12. Wang, H.; Wang, H.; Chen, K.; Song, Y.; Wei, Z.; Xue, M. The modification of lanthanum-exchanged montmorillonite with anionic surfactants to enhance the thermal stability of polyvinyl chloride. J. Appl. Polym. Sci. 2015, 132, 41535. [CrossRef]

13. Fu, M.; Zhang, Z.; Wu, L.; Zhuang, G.; Zhang, S.; Yuan, J.; Liao, L. Investigation on the co-modification process of montmorillonite by anionic and cationic surfactants. Appl. Clay Sci. 2016, 132-133, 694-701. [CrossRef]

14. Bertuoli, P.T.; Piazza, D.; Scienza, L.C.; Zattera, A.J. Preparation and characterization of montmorillonite modified with 3-aminopropyltriethoxysilane. Appl. Clay Sci. 2014, 87, 46-51. [CrossRef] 
15. Asgari, M.; Sundararaj, U. Silane functionalization of sodium montmorillonite nanoclay: The effect of dispersing media on intercalation and chemical grafting. Appl. Clay Sci. 2018, 153, 228-238. [CrossRef]

16. Bhanvase, B.A.; Pinjari, D.V.; Gogate, P.R.; Sonawane, S.H.; Pandit, A.B. Synthesis of exfoliated poly(styrene-co-methyl methacrylate)/montmorillonite nanocomposite using ultrasound assisted in situ emulsion copolymerization. Chem. Eng. J. 2012, 181-182, 770-778. [CrossRef]

17. Mirzataheri, M.; Khamisabadi, S.; Salimi, A. Characterization of styrene-co-butyl acrylate/Cloisite $\mathrm{Na}^{+}$ nanocomposite film synthesized via soap free emulsion polymerization. Prog. Org. Coat. 2016, 99, 274-281. [CrossRef]

18. Bourgeat-Lami, E.; Lansalot, M. Organic/inorganic composite latexes: The marriage of emulsion polymerization and inorganic chemistry. Adv. Polym. Sci. 2010, 233, 53-123.

19. Yamamoto, T.; Kawaguchi, K.; Takahashi, Y. Particle size control in the soap-free emulsion polymerization of styrene by an oil-soluble initiator with a weakly acidic water-soluble initiator. Colloids Surf. A Physicochem. Eng. Asp. 2016, 502, 1-5. [CrossRef]

20. Hu, Z.; Yang, X.; Liu, J.; Yan, Y.; Wang, L.; Zeng, Y. An investigation of the effect of sodium dodecyl sulfate on quasi-emulsifier-free emulsion polymerization for highly monodisperse polystyrene nanospheres. Eur. Polym. J. 2011, 47, 24-30.

21. Hojiyev, R.; Ulcay, Y.; Celik, M.S.; Carty, W.M. Effect of CEC coverage of hexadecyltributylphosphonium modified montmorillonite on polymer compatibility. Appl. Clay Sci. 2017, 141, 204-211. [CrossRef]

22. Sun, J.; Zhuang, G.; Wu, S.; Zhang, Z. Structure and performance of anionic-cationic-organo-montmorillonite in different organic solvents. RSC Adv. 2016, 6, 54747-54753. [CrossRef]

23. Alvi, M.U.; Zulfiqar, S.; Yavuz, C.T.; Kweon, H.; Sarwar, M.I. Influence of aminosilane coupling agent on aromatic polyamide/intercalated clay nanocomposites. Ind. Eng. Chem. Res. 2013, 52, 6908-6915. [CrossRef]

24. Cao, X.; Pan, G.; Huang, P.; Guo, D.; Xie, G. Silica-coated core-shell structured polystyrene nanospheres and their size-dependent mechanical properties. Langmuir 2017, 33, 8225-8232. [CrossRef] [PubMed]

25. Chen, J.; Liu, H.; Hong, X.; Wang, M.; Cai, C.; Zhang, Q. Polystyrene/MMT nanocomposites prepared by soap-free emulsion polymerization with high solids content. Colloid Polym. Sci. 2012, 290, 1955-1963. [CrossRef]

26. Angaji, M.T.; Rafiee, R.; Hemmati, M.; Abdollahi, M.; Razavi Aghjeh, M.K. Parametric studies on the grafting of poly (methyl methacrylate) onto organophilic montmorillonite using silylated clay platelets. J. Macromol. Sci. Part B 2014, 53, 957-974. [CrossRef]

27. Park, S.; Kim, B.; Seo, D.; Rhee, K.; Lyu, Y. Effects of a silane treatment on the mechanical interfacial properties of montmorillonite/epoxy nanocomposites. Mater. Sci. Eng. A 2009, 526, 74-78. [CrossRef]

28. Benbayer, C.; Saidi-Besbes, S.; Taffin De Givenchy, E.; Amigoni, S.; Guittard, F.; Derdour, A. Synergistic effect of organoclay fillers based on fluorinated surfmers for preparation of polystyrene nanocomposites. J. Appl. Polym. Sci. 2015, 132, 1-12. [CrossRef]

29. Zhang, Z.; Zhang, J.; Liao, L.; Xia, Z. Synergistic effect of cationic and anionic surfactants for the modification of Ca-montmorillonite. Mater. Res. Bull. 2013, 48, 1811-1816. [CrossRef]

30. Wu, S.; Zhang, Z.; Wang, Y.; Liao, L.; Zhang, J. Influence of montmorillonites exchange capacity on the basal spacing of cation-anion organo-montmorillonites. Mater. Res. Bull. 2014, 59, 59-64.

31. Silva, T.F.; Soares, B.G.; Ferreira, S.C.; Livi, S. Silylated montmorillonite as nanofillers for plasticized PVC nanocomposites: Effect of the plasticizer. Appl. Clay Sci. 2014, 99, 93-99. [CrossRef]

32. Xie, W.; Gao, Z.; Pan, W.P.; Hunter, D.; Singh, A.; Vaia, R. Thermal degradation chemistry of alkyl quaternary ammonium montmorillonite. Chem. Mater. 2001, 13, 2979-2990. [CrossRef]

33. Romanzini, D.; Piroli, V.; Frache, A.; Zattera, A.J.; Amico, S.C. Sodium montmorillonite modified with methacryloxy and vinylsilanes: Influence of silylation on the morphology of clay/unsaturated polyester nanocomposites. Appl. Clay Sci. 2015, 114, 550-557. [CrossRef]

34. Yu, C.; Ke, Y.; Deng, Q.; Lu, S.; Ji, J.; Hu, X.; Zhao, Y. Synthesis and characterization of polystyrene-montmorillonite nanocomposite particles using an anionic-surfactant-modified clay and their friction performance. Appl. Sci. 2018, 8, 964. [CrossRef]

35. Romanzini, D.; Frache, A.; Zattera, A.J.; Amico, S.C. Effect of clay silylation on curing and mechanical and thermal properties of unsaturated polyester/montmorillonite nanocomposites. J. Phys. Chem. Solids 2015, 87, 9-15. [CrossRef] 
36. Zhang, J.; Gupta, R.K.; Wilkie, C.A. Controlled silylation of montmorillonite and its polyethylene nanocomposites. Polymer 2006, 47, 4537-4543. [CrossRef]

37. Bourgeat-Lami, E.; Guimara, T.R.; Pereira, A.M.C.; Alves, G.M.; Moreira, J.C.; Putaux, J.; Santos, A.M. High solids content, soap-free, film-forming latexes stabilized by laponite clay platelets. Macromol. Rapid Comm. 2010, 31, 1874-1880. [CrossRef]

38. Ianchis, R.; Donescu, D.; Petcu, C.; Ghiurea, M.; Anghel, D.F.; Stanga, G.; Marcu, A. Surfactant-free emulsion polymerization of styrene in the presence of silylated montmorillonite. Appl. Clay Sci. 2009, 45, 164-170. [CrossRef]

39. Ianchis, R.; Corobea, M.C.; Donescu, D.; Rosca, I.D.; Cinteza, L.O.; Nistor, L.C.; Vasile, E.; Marin, A.; Preda, S. Advanced functionalization of organoclay nanoparticles by silylation and their polystyrene nanocomposites obtained by miniemulsion polymerization. J. Nanopart. Res. 2012, 14, 1233. [CrossRef]

40. Bee, S.L.; Abdullah, M.A.A.; Mamat, M.; Bee, S.T.; Sin, L.T.; Hui, D.; Rahmat, A.R. Characterization of silylated modified clay nanoparticles and its functionality in PMMA. Compos. Part B: Eng. 2017, 110, 83-95. [CrossRef]

41. Wang, L.; Wang, X.; Chen, Z.; Ma, P. Effect of doubly organo-modified vermiculite on the properties of vermiculite/polystyrene nanocomposites. Appl. Clay Sci. 2013, 75-76, 74-81. [CrossRef]

42. Chen, S.; Lu, X.; Zhang, Z.; Wang, T.; Pan, F. Preparation and Characterization of Poly(methyl methacrylate)/Reactive Montmorillonite Nanocomposites. Polym. Composite 2016, 37, 2396-2403. [CrossRef]

43. Sui, T.; Song, B.; Zhang, F.; Yang, Q. Effects of functional groups on the tribological properties of hairy silica nanoparticles as an additive to polyalphaolefin. RSC Adv. 2016, 6, 393-402. [CrossRef]

44. Sui, T.; Song, B.; Wen, Y.; Zhang, F. Bifunctional hairy silica nanoparticles as high-performance additives for lubricant. Sci. Rep. 2016, 6, 22696. [CrossRef] [PubMed]

(C) 2019 by the authors. Licensee MDPI, Basel, Switzerland. This article is an open access article distributed under the terms and conditions of the Creative Commons Attribution (CC BY) license (http://creativecommons.org/licenses/by/4.0/). 